\title{
Assessing Student's Acceptance of Digital Transformation in Business and Management Universities in Vietnam
}

\author{
Ha Thu Luong* \\ School of Advanced Educational Programs, National Economics University, Hanoi, Vietnam \\ 207 Giai Phong Street, Hai Ba Trung District, Hanoi 100000, Vietnam \\ Email: haluongthu@neu.edu.vn \\ Long Tien Bui \\ School of Advanced Educational Programs, National Economics University, Hanoi, Vietnam \\ 12A Cat Linh Street, Dong Da District, Hanoi 100000, Vietnam \\ Email: tienlongbui28@gmail.com \\ Dat Xuan Vu \\ School of Advanced Educational Programs, National Economics University, Hanoi, Vietnam \\ 69 Tho Quan Alley, Kham Thien Street, Dong Da District, Hanoi, Vietnam \\ Email: vuxuandat2110@gmail.com \\ Hang Thu Lai \\ School of Advanced Educational Programs, National Economics University, Hanoi, Vietnam \\ A3, 128C Alley, Dai La Street, Hai Ba Trung District, Hanoi, Vietnam \\ Email: hanglth1605@gmail.com
}

\begin{abstract}
In recent years, the trend of digital transformation in education has increased significantly. A series of policies to promote the digital transformation of education have been issued, gradually completing the legal corridor such as the regulations on applying information technology, information in management, organization of online training, the use of the entire industry database system. Therefore, this article is the result of a more comprehensive research project and aims to analyze the digital transformation acceptance of college students in Economic - Business Universities in the North of Vietnam. The Unified Theory of Acceptance and Use of Technology (UTAUT) and independent variable Perceived Security (PS) have been combined together in order to support the survey. The data was analyzed using the method of multiple regression. These findings shed the light on the digital transformation acceptance level of students with the positive link of Performance Expectancy (PE), Social Influence (SI), Perceived Security (PS) and Facilitating Conditions (FC) on Behavioral Intention of digital transformation and its Use Behavior. Moreover, the study also has the contribution to provide orientations and solutions that will be proposed to approach the trend encouraging the application of digital transformation into higher education specifically in the business field.
\end{abstract}

Keywords: UTAUT, digital transformation, perceived security, higher education

DOI: $10.7176 / \mathrm{JESD} / 12-8-02$

Publication date: April $30^{\text {th }} 2021$

\section{Introduction}

Digital transformation is an inevitable trend which is rapidly developing, especially in the context of the current Industrial Revolution 4.0. During the Industrial Revolution 4.0, a large number of countries around the world such as the UK, Australia, the US... have been implementing national strategies for comprehensive digital transformation. The digital transformation process extends across areas such as: Digital government (online public services, accessible data...), digital economy (Digital finance, e-commerce ...), digital society (education, health, culture...).

Not beyond the upward trend of the world, digital transformation in higher education in Vietnam is taking place strongly to catch up with the global education trend. Additionally, the effects from the Covid-19 pandemic once again affirm the role of technology in educational activities and urgent requirement for education to reform. In order to succeed in the procedure of digital transformation in education, particularly in higher education, the mindset of students and teachers have to be transformed. Since then teachers and students will have awareness that digital transformation provides a host of values, the opportunities to change and access the knowledge. Digital transformation acceptance must become the personal needs of each person.

As a result, research about Digital Transformation acceptance of students in Economics Business - Case of Higher Education in North Vietnam have an essential role to encourage and uphold the intention to use and use behavior of digital transformation applications of college students along with having contributed to promote the 
process of National digital transformation and sustainable economic development.

\section{Theoretical framework}

\subsection{UTAUT}

It was not long ago when the growth of IS/IT has proliferated. A numerous theories and models have been scrutinized in order to examine the behavioral intention of users in the field of IS/IT (information system/information technology). For example: technology acceptance model, theory of research action, later extended to technology acceptance model 2 and theory of planned behavior, respectively. These models and theories in general explain around 40 percent of individual intention to use technology (Venkatesh and Davis 2000). However, researchers have encountered multiple choices of model and made decisions on which model is the best for their study.

To make a clear and concise miniature, Venkatesh et al. with his partner proposed a unified model called unified theory of acceptance and use of technology as a result of comparing and validating eight different models: the social cognitive theory (SCT), the technology acceptance model (TAM), the theory of planned behavior (TPB), the combined of technology acceptance model (TAM) and theory of planned behavior model (TPB), the motivation model (MM), the model of PC utilization (MPCU), and the innovation diffusion theory (IDT). This model has been validated and accounted for up to 70 percent of the variables and it is superior compared to other antecedents models and theories (Venkatesh and David, 2003). The UTAUT model contains four main independent constructs, namely, performance expectancy (PE), effort expectancy (EE), social influence (SI), facilitating conditions (FC) and two dependent variables behavioral intention (BI) and use behavior (UB). The relationship between four independent and two dependent are moderated by gender, sex, age, the voluntariness of use.

\subsection{UTAUT in Digital Transformation}

There have been many studies using the UTAUT model in areas of technology application. Specifically, in the health sector, banking, transport, manufacturing, ... and indispensable is education. Research by Wissal Ben, Imed Ben Nasr, Galina Kondrateva and Lubica Hikkerova (2021) examined factors influencing patient's use of the Internet of Things for Electronic Health. Developed an application of the UTAUT model together with the risk trust relational variable have predicted intentions of using Internet of Things in the medical context. Or Boonchai Kijsanayotin, Supasit Pannarunothai, Stuart M. Speedie (2009) have employed UTAUT to understand the influencing factors to health IT adoption in Thailand's community health centers; James Tetteh Ami-Narh, Patricia A H Williams (2012) used UTAUT model to see the acceptance of Ehealth in Africa's health professionals. Moreover, in the public transportation sector, Louw, T, Dziennus, M et al. (2017) used UTAUT to find out the public acceptance of Automated Road Transport Systems; Danial Jahanshahi, Zahra Tabibi, Bert van Wee also applied this model to see the factors that influenced the acceptance and use of bicycle sharing system in Iran. In banking context, several of research applied UTAUT model to explain mobile banking adoption by users (Tao Zhou, Yaobin Lu, Bin Wang (2010)); understanding of mBanking (mobile banking) adoption by Tiago Oliveira, Miguel Faria, Manoj Abraham Thomas, Aleš Popovič in 2014. In education, many studies on mobile learning in Thailand (2009), Guyana (2013), UK (2013) and Saudi Arabia (2013); E-learning in Turkey (2018), Slovenia (2015); some other studies using theory to study 3D printing technology. Therefore, this article aims to apply and expand research to test and prove the suitable in the context of higher education specialized in the economic sector in Vietnam today.

\subsection{Perceived Security}

During the $4.0 \mathrm{era}$, in universities, when applying digital transformation, perceived security is considered as an important factor affecting the process of technology adoption and use. In Higher Education, it is becoming more common to search information as well as provide personal information to the school system to collect and process data. Therefore, the perceived security in the digital transformation is the matter of great import for users. In general, perceived security is defined as the subjective perception of online users who believe that all of their personal information will be kept safe from the risks involved in storing and processing information online. Arpaci et al. have studied the impact of security on educational use of cloud services. The results support the proposed model, confirm the predictability of TPB and indicate that security and privacy have a significant effect on students' attitudes towards using cloud services in educational envionment. Research by Lai Fong Won (2011) identified that security like privacy, and trust on the website are significantly related to the willingness to share Information in Higher Education Institutions. It can be seen that security plays an important role in building a solid digital transformation platform for Universities. As digital transformation is developing, it will bring many effects and benefits to $t$ education, especially Higher Education. In order to grow and be well-received by users, information security must be given special attention to increase trust in influencing the user's perception and readiness of use. 


\section{Research model and hypothesis}

\subsection{Research model}

The research aimed at explaining the acceptance and use of digital transformation of students in Economics Business. For the study, it adopted and developed the Unified Theory of Acceptance and Use of Technology (UTAUT - model developed by Venkatesh et al (2003)). In the original model, there are 4 impact variables: Performance Expectancy (PE); Effort Expectancy (EE); Social Influence (SI); Facilitating Conditions (FC). After doing the research, Perceived Security (PS) is added due to the appropriateness of the research and made an argument that the independent variables (PE, EE, SI, FC, PS) all have positive effects on Use Behavior (UB). Therefore, a new research model is proposed and a detailed explanation of each Hypothesis is also presented:

Figure 1. Model of factors affecting student's digital transformation use behavior

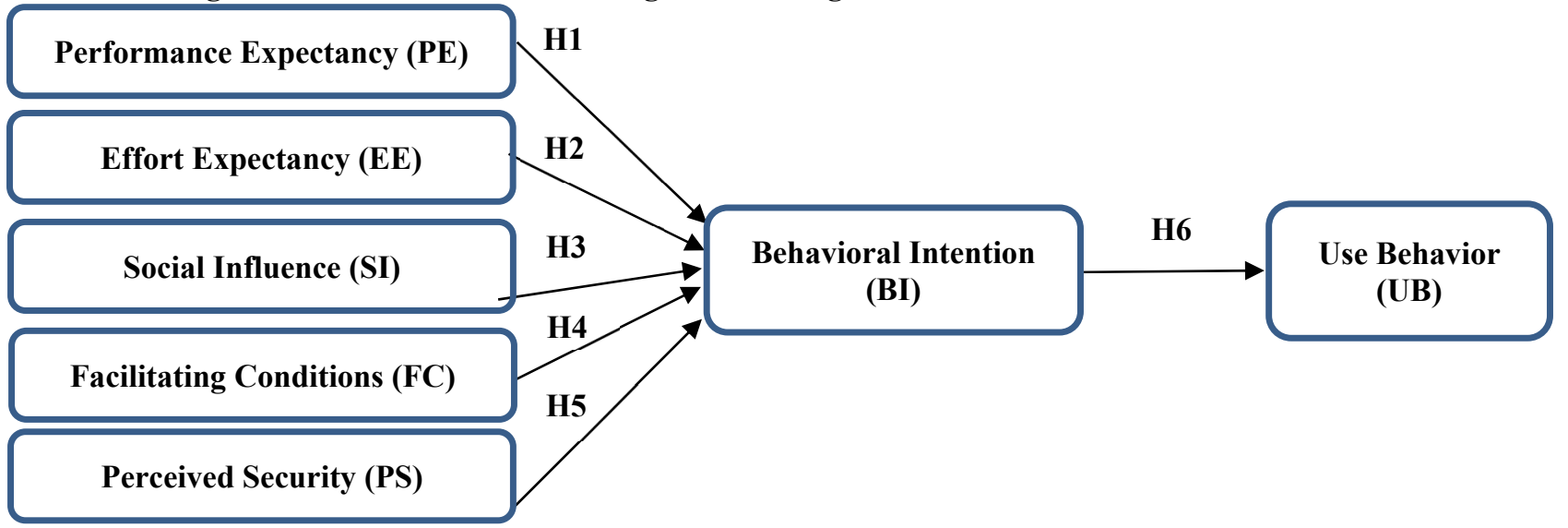

(Source: Authors)

\subsection{Hypothesis}

\subsubsection{Performance Expectancy (PE)}

In UTAUT, the Performance Expectancy, according to Venkatesh is defined as the ease when users believe that applying the system will help gaining their performance. More specifically, in this research, Performance Expectancy indicates the extent to which Digital Transformation helps students improve their studies in Higher education, for example applying Digital Transformation to access to more information in learning, therefore increase productivity, work efficiency. In previous research by Troy Devon Thomas, Lenandlar Singh and Kemuel Gaffar (2013), Performance Expectancy is the determinant of Behavioral Intention while using technology. In the scope of Digital Transformation, when people believe Digital Transformation enables them in increasing their performance, they are more likely to adopt the technology. Therefore, we proposed that:

\section{H1: Performance Expectancy positively affect Behavioral Intention to accept digital transformation}

\subsubsection{Effort Expectancy (EE)}

Effort Expectancy is defined as the degree of ease with the system use. According to Venkatesh, this factor is due to the conspicuousness of coefficients used in the Technology Acceptance Model (TAM). The acceptance will be easier to occur when people feel the ease with the application (David et al. (1989). Older research have reported that Effort Expectancy has the relationship with the technology adoption and Performance Expectancy. When users believe that Digital Transformation is easy and effortless, they will expect a better performance at their work, therefore more likely to accept and use it. We proposed that:

\section{H2: Effort Expectancy positively affect Behavioral Intention to accept digital transformation}

\subsubsection{Social Influence (SI)}

The Social Influence in UTAUT is the degree an individual perceives that the important people (for example their family, friends or the superior) believe that using technology is necessary (Venkatesh et al., 2003). The rationale behind this is due to the fact that these people aim to strengthen their relationship with people who are important to them by considering as well as receiving recommendations. For example, in this research, the University or family members encourage students in the Digital Transformation application process. Previous research showed that Social Influence is a significant permise. Users are more likely to accept Digital Transformation if other important people recommend it. Therefore, we proposed:

\section{H3: Social Influence positively affect Behavioral Intention to accept digital transformation}

\subsubsection{Facilitating conditions (FC)}

The Facilitating Conditions refers to an individual's perception of the degree to which organization and technical infrastructure are ready to assist when applying the new technology in their work. In this research, by focusing on skills, knowledge and other support, students will be likely to apply Digital Transformation. For example, accessible devices are required in the process of Digital Transformation in Higher education. Previous research 
indicated Facilitating Conditions increase will improve Behavioral Intention. Moreover, with higher facilitation, the effort required to apply Digital Transformation will decrease. When there are sufficient supporting resources (like the techniques guided by experts), people will find it easy to use. Therefore, we proposed that:

\section{H4: Facilitating Conditions positively affect the Behavioral Intention in digital transformation}

\subsubsection{Perceived Security (PS)}

Perceived Security is defined as the degree which an individual believes that their information will be secured without being stored, viewed while applying technology (Mekovec, R. \& Hutinski, Z., 2012). The risks to website and mobile platforms are various. According to Arpaci et al. (2015), Perceived Security direct impact on the attitude, therefore affected the adoption intention. In this study, Perceived Security has a great effect on the readiness of use. For example, when students believe that Digital Transformation is safe to interact or protect their personal information, they will be ready to apply. With a secured platform, the insecurities and concern will be lessened. Therefore, we proposed that:

\section{H5: Perceived Security positively affect the Behavioral Intention in digital transformation}

\section{Research methodology}

\subsection{Data collection method}

In this study, a quantitative approach with a questionnaire survey was conducted. Data was collected using both online and offline surveys. To test the instrument, a pilot study was conducted among a group of 20 college students and teachers who were not included in the main survey. Preliminary evidence showed that the scales were reliable and valid, with the exception of 4 items with low loading (FC3, FC4, FC5, SI5) that were removed from the questionnaire. These loadings are less than 0.50 , for these reasons were eliminated. The data collection was performed during November 2020 by distributing self-administered questionnaires among students, teachers, employees in five Northern-economics-business universities namely, National Economics University, Foreign Trade University, Vietnam Commercial University, Banking Academy, Academy of Finance. Overall, 600 offline questionnaires were distributed among the students. 699 questionnaires including 438 offline and 261 online were received. Accordingly, 539 valid questionnaires (361 offline and 178 online) were included in the primary analysis with a response rate of approximately 77\%. 160 questionnaires were dropped due to the large number of missing values and invalidity, 85 questionnaires were lost during the procedure of offline survey.

\subsection{Structure questionnaire}

Table 1. Variables and Items

\begin{tabular}{|c|c|}
\hline Variables/Items & Authors \\
\hline $\begin{array}{l}\text { Performance Expectancy (PE) } \\
\text { I would find the use of digital transformation is useful for learning. } \\
\text { Using digital transformation would enable me to accomplish learning tasks } \\
\text { more quickly. } \\
\text { Using digital transformation would increase my productivity while } \\
\text { learning. } \\
\text { Using digital transformation would increase the effect of my learning. } \\
\text { Using digital transformation would help me solve unfortunate problems in } \\
\text { my learning. } \\
\text { The use of digital transformation will allow me to have access to more } \\
\text { information about my learning. }\end{array}$ & $\begin{array}{l}\text { Venkatesh et al. (2003) } \\
\text { Mtebe, J. S., \& Raisamo, R. } \\
\text { (2014) } \\
\text { Parameswaran, S., Kishore, R., \& } \\
\text { Li, P. (2015) } \\
\text { Šmak, B., \& Šorgo, A. (2016) } \\
\text { Madigan, R., Louw, T., Wilbrink, } \\
\text { M., and Schieben, A. (2017) }\end{array}$ \\
\hline $\begin{array}{l}\text { Effort Expectancy (EE) } \\
\text { My interaction with digital transformation is clear and understandable. } \\
\text { It would be easy for me to become skillful at using digital transformation. } \\
\text { Learning to operate digital transformation will be easy for me. } \\
\text { I can quickly and easily utilize the use of digital transformation. } \\
\text { I do not have any doubts about what I'm doing when I'm using the services } \\
\text { of digital transformation. }\end{array}$ & $\begin{array}{l}\text { Venkatesh et al. (2003) } \\
\text { Parameswaran, S., Kishore, R., \& } \\
\text { Li, P. (2015) } \\
\text { Šumak, B., \& Šorgo, A. (2016) } \\
\text { Dakduk, S., Santalla-Banderali, } \\
\text { Z., \& van der Woude, D. (2018) }\end{array}$ \\
\hline
\end{tabular}




\section{Variables/Items}

\section{Authors}

Social Influence (SI)
People who are important to me will think that I should use digital
transformation.
People who influence my behaviour think that I should use digital
transformation in my work.
The senior management of the school (teachers) would be helpful in the use
of digital transformation.
In general, the school environment would be supportive towards the use of
digital transformation.
Using digital transformation makes me feel that I belong to the era 4.0 .

\section{Facilitating Conditions (FC)}

I would have mobile devices necessary to use digital transformation.

I would have the knowledge necessary to use digital transformation.

A specific person (or group) would be available for assistance with digital transformation difficulties.

Digital transformation would be compatible with other systems I use for teaching.

I have control over the digital transformation process.

\section{Perceived Security (PS)}

Digital transformation application is safe to interact with for financial purposes.

Digital transformation application protects my account information.

Digital transformation apps do not share my personal information with other sites.

\begin{tabular}{ll}
\hline Behavioral Intention (BI) & Venkatesh et al. (2003) \\
\hline I predict I will use digital transformation in the future. & \\
I intend to use digital transformation in the future. & \\
I plan to use digital transformation in the future. & Venkatesh et al. (2003) \\
\hline Use Behavior (UB) & Parameswaran, S., Kishore, R., \& \\
\hline I would use digital transformation frequently. & Li, P. (2015) \\
If available, I would use digital transformation & \\
Digital transformation is an essential part of my daily work (in the future). & \\
\hline
\end{tabular}

(Source: Authors)

\subsection{Sample description}

Out of 539 questionnaires that were tested, two-third of students were female which occupied approximately $69 \%$, whereas, the number of male students were only $29 \%$. According to the studying year, freshmen were the largest figure with 223 questionnaires, the second position was taken by juniors with a total of 173 questionnaires, there were 95 questionnaires from sophomores and just only 48 questionnaires belonged to seniors. For the figure of students according to the area, the number of students from KV1 (the communes of area I, II, III in ethnic minority and mountainous areas according to current regulations corresponding to the candidate's time of high school or intermediate school; communes with extreme difficulty in coastal areas and islands; communes with extreme difficulties, border communes and safe areas are included in the investment category of Program 135 according to regulations of the Prime Minister) was 72 - the lowest out of four areas, 185 questionnaires were the figure for both students from KV2 (towns and cities directly under the province; towns, suburban districts of centrallyaffiliated cities except for communes in KV1) and KV3 (urban districts of centrally-affiliated cities), and there were 97 questionnaires from students of KV2-NT (the localities not belonging to KV1, KV2, KV3).

The research team used SPSS to analyze collected data from students in economics university. Descriptive analyses such as frequencies, means, standard deviations, and correlations were run to examine sample profiles and to determine the extent of relationships among the variables. Secondly, a multiple linear regression analysis was conducted to explore the research questions posed regarding the extent to which the four constructs explain the variance in teachers' behavioural intentions to adopt Classe21. This relationship was examined with and without the inclusion of the proposed moderator variables age, gender, teaching experience and post-graduate 
qualification in education/technology.

\section{Data Analysis}

\subsection{Reliability and Validity tests}

In this research, all Cronbach's alpha values were larger than 0.7 , which indicates a reliable questionnaire among the variables.

Table 2. Reliability and analysis results

\begin{tabular}{|c|c|c|c|c|}
\hline \multirow{2}{*}{$\begin{array}{c}\text { Code } \\
\text { Name }\end{array}$} & Factor Name & \multicolumn{2}{|c|}{ Number of observed variables } & \multirow{2}{*}{ Cronbach's Alpha } \\
\cline { 3 - 4 } & & Before & After & \\
\hline PE & Performance expectancy & 6 & 6 & 0.864 \\
\hline EE & Effort expectancy & 5 & 5 & 0.813 \\
\hline SI & Social Influence & 5 & 4 & 0.766 \\
\hline FC & Facilitating Conditions & 5 & 2 & 0.748 \\
\hline PS & Perceived Security & 3 & 3 & 0.823 \\
\hline BI & Behavioral Intention & 3 & 3 & 0.890 \\
\hline UB & Use Behavior & 3 & 3 & 0.864 \\
\hline
\end{tabular}

(Source: Research results)

\subsection{Exploratory factor analysis (EFA)}

Exploratory factor analysis (EFA) was carried out by using the method Principle components analysis and Varimax rotation. The first EFA analysis result eliminated SI5, FC3, FC4, FC5 because the loading factor is less than 0.5. Continuing to analyse EFA the second time, the factor loading result was satisfactory in all the criteria. Inspection result $\mathrm{KMO}=0.878$ and Barlett's result have Sig. $=0.000$, the number of factors extracted is 5 factors, total variance extracted of $65.260 \%$, the number of all factors was greater than 0.5 . At this point, 8 key groups of factors from the original hypothetical model have been replaced.

Based on analysis results with Eigenvalue standard are greater than 1, the two scales of behavioral intention and use behaviour fall into one group, this can be easily explained because of the compulsory training in institutions, students also have to force themselves to follow better things to help their learning purposes. As regard to that merge, we decided to eliminate behavioral intention scale and use the use behavioral as a main dependant variable:

- 5 Independent Factors: PE, EE, SI, PS, FC

- 1 Dependent Factor: UB

\subsection{Hypothesis testing}

The results of Pearson's correlation analysis show that there exists are linear correlation between the dependent variable Y and the independent variables PE, EE, SI, FC, PS (Sig.< 0.05). Result of linear regression analysis the effect between the factors affecting digital transformation use behavior with $5 \%$ significance indicate the relationship of 4 independent variables (X1) Performance expectancy, (X3) Social influence, (X4) Perceived security, (X5) Facilitating condition on dependent variables (Y) Use behavior (Sig. $<0.05)$, the coefficient $\mathrm{R}^{2}$ adjusted to 0.481 means that the linear regression model was built in accordance with the data set at $48.1 \%$. Next, the VIF coefficient of the independent variables is less than 2, so no collinearity phenomenon occurs. The analysis results show that the SIG value of the F-test is very small $\left(0.000^{b}\right)$.

To evaluate the suitability of the overall linear regression model, we use the F-test in the table of variance analysis (ANOVA). The analytical results showed that the value of Sig. for the F-test is very small $(=0.000 \mathrm{~b})$, which means that there is a basis to refuse Ho that the regression coefficients are zero. Thus, the linear regression model was suitable overall. 
Table 3. The regression results

\begin{tabular}{|l|r|r|c|r|r|r|r|}
\hline \multicolumn{9}{|c|}{ Coefficients $^{\mathbf{a}}$} \\
\hline Model & \multicolumn{2}{|c|}{$\begin{array}{c}\text { Unstandardized } \\
\text { Coefficients }\end{array}$} & $\begin{array}{l}\text { Standardized } \\
\text { Coefficients }\end{array}$ & \multicolumn{1}{c|}{$\mathrm{t}$} & \multicolumn{1}{c|}{ Sig. } & \multicolumn{2}{c|}{ Collinearity Statistics } \\
\hline & $\mathrm{B}$ & Std. Error & Beta & & & Tolerance & \multicolumn{1}{c|}{ VIF } \\
\hline (Constant) & .305 & .166 & & 1.843 & .066 & & \\
\hline PE & .371 & .039 & .351 & 9.513 & .000 & .707 & 1.414 \\
\hline EE &. .020 & .042 & -.019 & -.464 & .642 & .588 & 1.702 \\
\hline SI & .282 & .041 & .259 & 6.880 & .000 & .680 & 1.470 \\
\hline PS & .159 & .027 & .198 & 5.821 & .000 & .835 & 1.197 \\
\hline FC & .171 & .035 & .182 & 4.942 & .000 & .709 & 1.411 \\
\hline
\end{tabular}

a. Dependent Variable: UB

(Source: Research results)

Figure 2. Model of research on factors affecting student's digital transformation use behavior appliances in Vietnam

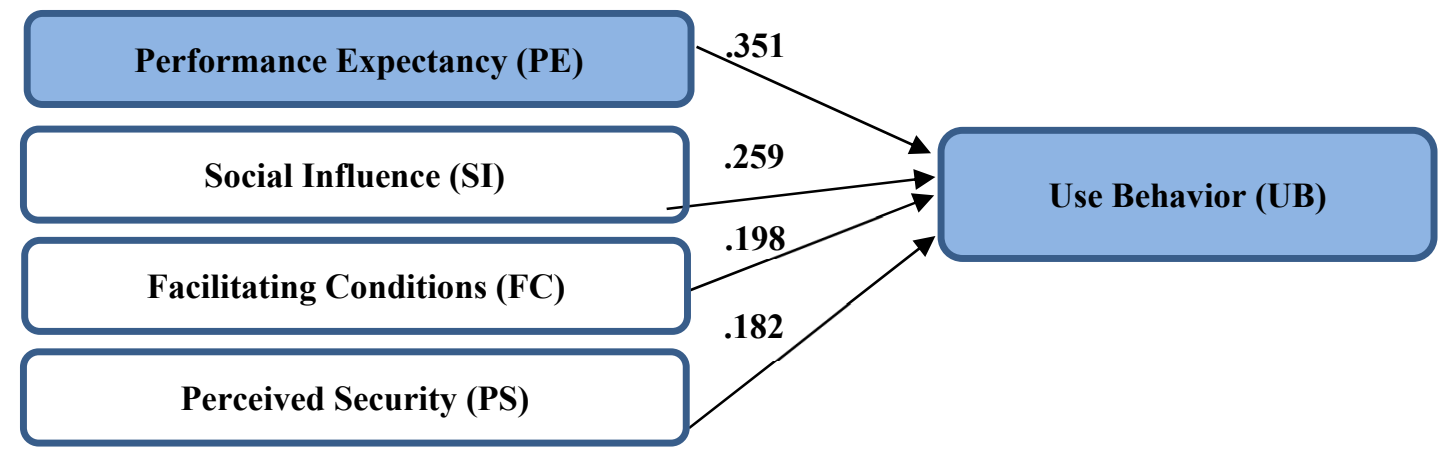

(Source: Research results)

The regression results assessing the impact of 5 factors on $(\mathrm{Y})$ Use behavior as follows:

$$
\mathrm{Y}=0.351(\mathrm{X} 1)+0.259(\mathrm{X} 3)+0.198(\mathrm{X} 4)+0.182(\mathrm{X} 5)
$$

This indicates that, with the significance of $5 \%$ there are 4 factors impact on digital transformation acceptance and use behavior, the impact level of 4 factors in descending order are: (1) (PE) Performance expectancy $(\beta=0.351)$, (2) (SI) Social influence $(\beta=0.259)$, (3) (PS) Perceived security $(\beta=0.198)$, (4) (FC) Facilitating condition ( $\beta=0.182$ ). The standardized coefficients $\beta>0$ show a positive relationship between the independent variables and green consumption behavior. In which, factor (PE) Performance expectancy is assessed as having the strongest impact on use behavior and the weakest factor impact on use behavior is (FC) Facilitating condition.

\section{Conclusion and Recommendation}

The research shows that 4 among 5 factors are affecting the acceptance and use behavior of digital transformation for students in higher education in Vietnam. Two variables named "Performance expectancy" and "Social influence" are respectively the two strongest factors, followed by Perceived security and Facilitating condition. It can be seen that student's mindset about digital transformation is elevated as it is partly influenced by social influence and the requirement of the era 4.0; thus, they are keen on using digital transformation in higher education.

For students, the application of information technology (IT) in the learning process is no longer a new thing. However, to be able to apply thoroughly and effectively, students need to prepare knowledge and skills for themselves. First, students need a holistic understanding of digital transformation in education by taking part in some short-term training courses. Regularly update information and instructions of the Government in the current digital transformation to improve their understanding. Next, it is necessary to be conscious, preparing for the basic skills. In addition, it is possible to propose to teachers, administrators about training skills to use proficient platforms, applications or how to access data and information during the studying time at school. .

Besides that, giving feedback to the school to contribute to a more comprehensive system is also extremely important. In addition, students should learn carefully about the source of searching information, the applications or the learning platform to be able to make use of their own research and learning, to avoid information bias or loss and the control of personal security. Finally, realizing the urgency of digital transformation, students can 
encourage their friends and relatives to apply digital transformation and hone their IT skills to apply technology as a useful form of support to increase productivity.

\section{Limitations and future research directions}

Firstly, our study only examined digital transformation acceptance in higher education specifically in the North of Vietnam among 5 economic universities, this study general and failed to discriminate acceptance by various types of digital transformation. Another limitation of this study belongs to the investigative sample. Due to being selected according to the convenient method, the research team has tried to be represented in five universities including: National Economics University, Foreign Trade University, Vietnam Commercial University, Banking Academy, Academy of Finance, with a variety of studying years and student areas, however, the sample can not provide any assurance in the representativeness or generality requirements.

Because digital transformation in higher education covers many complex aspects, it is necessary to have more in-depth studies in order to continue to build and complete a scale of factors affecting the behavior of accepting digital transformation in higher education. Second, to improve the representativeness and generality of the stated conclusions, it is necessary to expand the sample size. Sample selection and testing process should be done more scientifically and selectively.

\section{References}

[1] Venkatesh, V., Morris, M. G., Davis, G. B., \& Davis, F. D. (2003). User acceptance of information technology: Toward a unified view. MIS quarterly, 425-478.

[2] Kallaya, J., Prasong, P., \& Kittima, M. (2009). An acceptance of mobile learning for higher education students in Thailand.

[3] Thomas, T.D., Singh, L., and Gaffar, K. (2013). The utility of the UTAUT model in explaining mobile learning adoption in higher education in Guyana. International Journal of Education and Development using Information and Communication Technology (IJEDICT), 9(3), 71-85.

[4] Madigan, R., Louw, T., Wilbrink, M., and Schieben, A. (2017). What influences the decision to use automated public transport? Using UTAUT to understand public acceptance of Automated Road Transport Systems. Transportation Research Part F: Traffic Psychology and Behaviour, 50, 55-64.

[5] Almadhoun, N. M., Dominic, P. D. D., \& Woon, L. F. (2011, November). Perceived security, privacy, and trust concerns within Social Networking Sites: The role of Information sharing and relationships development in the Malaysian Higher Education Institutions' marketing. In 2011 IEEE International Conference on Control System, Computing and Engineering (pp. 426-431). IEEE.

[6] Mekovec, R., \& Hutinski, Ž. (2012, May). The role of perceived privacy and perceived security in online market. In 2012 Proceedings of the 35th International Convention MIPRO (pp. 1549-1554). IEEE.

[7] Uğur, N. G., \& Turan, A. H. (2018). E-learning adoption of academicians: a proposal for an extended model. Behaviour \& Information Technology, 37(4), 393-405.

[8] Dečman, M. (2015). Modeling the acceptance of e-learning in mandatory environments of higher education: The influence of previous education and gender. Computers in human behavior, 49, 272-281.

[9] Abu-Al-Aish, A., \& Love, S. (2013). Factors influencing students' acceptance of m-learning: An investigation in higher education. International Review of Research in Open and Distributed Learning, 14(5), 82-107.

[10] Nassuora, A. B. (2012). Students acceptance of mobile learning for higher education in Saudi Arabia. American Academic \& Scholarly Research Journal, 4(2), 24-30.

[11] Venkatesh, V., \& Davis, F. D. (2000). A theoretical extension of the technology acceptance model: Four longitudinal field studies. Management science, 46(2), 186-204.

[12] Bandura, A. (2001). Social cognitive theory of mass communication. Media psychology, 3(3), 265-299.

[13] Ami-Narh, J. T., \& Williams, P. A. (2012). A revised UTAUT model to investigate E-health acceptance of health professionals in Africa. Journal of Emerging Trends in Computing and Information Sciences, 3(10), 1383-1391.

[14] Arfi, W. B., Nasr, I. B., Kondrateva, G., \& Hikkerova, L. (2021). The role of trust in intention to use the IoT in eHealth: Application of the modified UTAUT in a consumer context. Technological Forecasting and Social Change, 167, 120688.

[15] Oliveira, T., Faria, M., Thomas, M. A., \& Popovič, A. (2014). Extending the understanding of mobile banking adoption: When UTAUT meets TTF and ITM. International journal of information management, 34(5), 689703.

[16] Jahanshahi, D., Tabibi, Z., \& Van Wee, B. (2020). Factors influencing the acceptance and use of a bicycle sharing system: Applying an extended Unified Theory of Acceptance and Use of Technology (UTAUT). Case Studies on Transport Policy, 8(4), 1212-1223.

[17] Madigan, R., Louw, T., Wilbrink, M., Schieben, A., \& Merat, N. (2017). What influences the decision to use automated public transport? Using UTAUT to understand public acceptance of automated road transport 
systems. Transportation research part F: traffic psychology and behaviour, 50, 55-64.

[18] Almaiah, M.A., Alamri, M.M., and Al-rahmi, W. (2019). Applying the UTAUT Model to Explain the Students' Acceptance of Mobile Learning System in Higher Education. IEEE Access, 7, 17463 - 174686.

[19] Vatanasombut, B., Igbaria, M., Stylianou, A. C., \& Rodgers, W. (2008). Information systems continuance intention of web-based applications customers: The case of online banking. Information \& management, 45(7), 419-428.

[20] Parameswaran, S., Kishore, R., \& Li, P. (2015). Within-study measurement invariance of the UTAUT instrument: An assessment with user technology engagement variables. Information \& Management, 52(3), 317-336.

[21] Šumak, B., \& Šorgo, A. (2016). The acceptance and use of interactive whiteboards among teachers: Differences in UTAUT determinants between pre-and post-adopters. Computers in Human Behavior, 64, 602-620.

[22] Dakduk, S., Santalla-Banderali, Z., \& van der Woude, D. (2018). Acceptance of blended learning in executive education. SAGE Open, 8(3), 2158244018800647.

[23] Mtebe, J. S., \& Raisamo, R. (2014). Challenges and instructors' intention to adopt and use open educational resources in higher education in Tanzania. International review of research in open and distributed learning, $15(1), 249-271$. 